Article

\title{
Intermittent colonisation with Methicillin-Resistant Staphylococcal aureus can be eradicated from the Airways of Adults with Cystic Fibrosis
}

\author{
Lucy Ranzenbacher ${ }^{1}$, Yang Song ${ }^{1,2}$, Alison Merchant ${ }^{2}$ and Peter G Middleton ${ }^{1,2, *}$ \\ 1 Department of Respiratory and Sleep Medicine, Westmead Hospital, Westmead, NSW 2145, Australia; \\ lucy.ranzenbacher@health.nsw.gov.au (L.R.); Yang.Song@health.nsw.gov.au (Y.S.) \\ 2 CF Research Group, Ludwig Engel Centre for Respiratory Research, Westmead Institute of Medical Research, \\ Westmead, NSW 2145, Australia; Alison.Merchant@health.nsw.gov.au \\ * Correspondence: peter.middleton@sydney.edu.au
}

Received: 15 July 2019; Accepted: 6 August 2019; Published: 9 August 2019

check for updates

\begin{abstract}
The airways of people with cystic fibrosis (CF) are chronically colonised with different pathogens. With recent interest in methicillin-resistant Staphylococcus aureus (MRSA), we have recently examined the rates of MRSA colonisation in different groups within our CF Service. This paper now examines the effectiveness of eradication strategies to clear the MRSA colonisation.
\end{abstract}

Keywords: cystic fibrosis; MRSA; eradication

\section{Introduction}

Cystic fibrosis (CF) is the most common lethal inherited disease in Australia. People with CF have characteristic colonisation of the airways with methicillin-sensitive Staphylococcus aureus (MSSA), methicillin-resistant Staphylococcus aureus (MRSA) and/or Pseudomonas aeruginosa (PsA). In our recent paper examining the risks of people with CF who were health care workers and in particular their risk of colonisation with MRSA, we collected data concerning eradication therapy, demographics, treatment details and outcomes [1]. Successful clearance rates of MRSA of up to $80 \%$ in early colonisation have been reported [2-4]. Our eradication process included both oral and intravenous antibiotics directed at the MRSA, together with topical mupirocin to the anterior nares to reduce local colonisation in the nasal passage.

\section{Results}

Over the period 2001-2015, a total of 252 patients were cared for at the Westmead Adult CF Service, Westmead NSW Australia. During this time, all sputum samples were cultured for the presence of MSSA, MRSA, Pseudomonas aeruginosa and other standard pathogens. Those who grew an organism on at least two occasions within 12 months were termed "colonised". This was further divided into those who were termed intermittent, where $<50 \%$ of the cultures were positive for the organism of concern (e.g., MRSA/MSSA/PsA), versus the chronic colonisations, where more than $80 \%$ of samples isolated the organism. The chronic and intermittent colonisation data is presented in Table 1.

Over the 2001-2015 period, a total of 20 adults with CF isolated MRSA on more than two occasions, of whom 12 were chronically colonised and eight were intermittently colonised. Further details of these MRSA colonised patients are shown in Table 2. 
Table 1. Colonisation rates for methicillin-sensitive Staphylococcus aureus (MSSA), methicillin-resistant Staphylococcus aureus (MRSA) and Pseudomonas aeruginosa (PsA), (rounding to whole number values).

\begin{tabular}{ccc}
\hline Organism & Chronic & Intermittent \\
\hline MSSA & $27 \%$ & $17 \%$ \\
MRSA & $5 \%$ & $3 \%$ \\
PsA & $58 \%$ & $10 \%$ \\
\hline
\end{tabular}

Table 2. Demographics of cystic fibrosis (CF) patients with chronic or intermittent MRSA colonisation.

\begin{tabular}{cccccc}
\hline Age & Gender & Occupation & MRSA & Status & Other Chronic Organism \\
\hline 30 & Male & Electrical Engineer & Chronic & Failed & PsA, coliform \\
25 & Male & Builder & Chronic & Eradicated & PsA \\
45 & Female & Unemployed & Chronic & Failed & nil \\
23 & Male & Personal Trainer & Chronic & Not Offered & nil \\
47 & Male & Jockey & Chronic & Failed & nil \\
41 & Female & Bus Driver & Chronic & Failed & PsA \\
41 & Male & Unemployed & Chronic & Eradicated & PsA \\
30 & Male & Unemployed & Chronic & Eradicated & PsA \\
30 & Female & Teacher & Chronic & Failed & nil \\
37 & Male & Teacher & Chronic & Failed & PsA \\
23 & Female & Student & Chronic & Failed & nil \\
29 & Female & Waiter & Chronic & Failed & PsA \\
47 & Female & Unemployed & Intermittent & Not Offered & PsA \\
38 & Female & Retail & Intermittent & Eradicated & PsA \\
24 & Male & University Student/Fireman & Intermittent & Eradicated & nil \\
30 & Male & Administration & Intermittent & Eradicated & PsA \\
27 & Male & Support Assistant & Intermittent & Not Offered & nil \\
29 & Female & Unemployed/Mother/Childcare & Intermittent & Not Offered & nil \\
30 & Female & Psychologist & Intermittent & Eradicated & PsA \\
30 & Female & Nurse & Intermittent & Eradicated & PsA \\
\hline
\end{tabular}

The summary of the characteristics as shown in Table 2 suggest that the intermittently colonised patients with CF were more likely to be successful in eradication. Out of the eight intermittently colonised patients, three were not offered eradication. Of the five patients who were offered MRSA eradication therapy, all five cleared MRSA. P. aeruginosa was the most common co-coloniser. Two out of the 20 patients were chronically colonised with other organisms, one with a coliform (not eradicated) and one with Haemophilus influenzae (eradicated). Both of these patients also grew PsA. There was a trend to better eradication of MRSA in those with concurrent PsA infection, but there was no statistical predictors for eradication: no difference in males versus females, older versus younger subjects, or co-colonisation with PsA. There was also no predilection for occupation or employment status, which has previously been discussed [1].

Out of the 20 patients colonised with MRSA, 16 were offered eradiation therapy. The four patients excluded from eradication therapy had previously shown non-compliance with other therapies and were deemed unsuitable for such a therapy regimen.

Of the 16 patients offered eradication therapy, eradication was successful in five of the five intermittently colonised subjects who were offered eradication therapy. Only three out of the eleven chronically colonised subjects achieved eradication.

The 16 medical records were examined with respect to dose and duration of oral and intravenous MRSA-targeted antibiotic therapy. Three records were incomplete and not suitable for analysis. The treatment records for these 13 remaining patients were analysed. Vancomycin was used intravenously whilst rifampicin and fucidin were oral preparations and the mucopiricin was a topical ointment. These details are displayed in Table 3. 
Table 3. Comparison of successful and failed MRSA eradication in those with complete data set.

\begin{tabular}{lcc}
\hline Variable & Eradicated & Failed \\
\hline Number of Adults & 6 & 7 \\
Average Age (years) & 28.83 & 26.7 \\
Number receiving vancomycin prior to eradication & 5 & 6 \\
Average number of courses of vancomycin & 4.2 & 10.3 \\
Average course length of vancomycin (weeks) & 15 & 23.3 \\
Average number of rifampicin / fucidin courses & 1.5 & 1.9 \\
Average duration of courses of rifampicin / fucidin (months) & 4.3 & 9.9 \\
PsA co-infection & $100 \%$ & $57.1 \%$ \\
\hline
\end{tabular}

\section{Discussion}

MRSA colonisation in the adult CF population is associated with poor outcomes $[5,6]$. The clearance of MRSA colonisation/infection from the airways of adults with CF is likely to be of assistance in the maintenance of good health. Eradication protocols vary between different clinics around the world. In general, the protocol used here included long-term rifampicin and fucidin, as described previously [7]. Difficulties with eradication protocols include drug interactions, side effects and toxicities [8]. The current experience with adherence also reflects the difficulties with long term complicated treatment protocols.

Successful eradication was achieved in those with intermittent colonisation and this likely reflects early infection with MRSA. Successful early clearance has been described previously [9], with clearance rates of $\sim 80 \%$ [2-4]. Of the individuals where eradication was successful, this typically occurred earlier in the course of treatment, and was reflected in a shorter duration of rifampicin/fucidin/mucopiricin.

Intravenous vancomycin was used in the majority of adults with MRSA colonisation who were symptomatic. Whilst the use of this agent did not appear to improve eradication, it was effective at clinical outcomes, suppressing the reaction to the MRSA colonisation.

PsA and MRSA co-infection occur in $60 \%$ of our population. Co-infection with these organisms is associated with a more rapid deterioration of lung function [10]. The challenges achieving eradication of chronic PsA colonisation in people with CF are widely described [11-13]. Given the poorer outcomes for co-infection and challenges with PsA eradication, we would therefore encourage eradication therapy targeting MRSA.

One individual underwent 2 prolonged periods of therapy directed at eradicating MRSA, which were unsuccessful. However, following extensive surgical management of his nasal polyposis, a further course of eradication therapy was successful. Recently, a combination of oral therapy and topical mupirocin ointment was described in those patients who were newly colonised with MRSA [4] demonstrating the diversity of eradication protocols in different clinics.

\section{Materials and Methods}

The Australian CF Data Registry (ACFDR) for the Westmead Clinic was searched to identify all adults who attended the clinic between 2001 and 2015. Demographic data on the patients including age, gender, $\mathrm{FEV}_{1}$, sputum colonisation and occupation were collected. Manual assessment of those with MRSA colonisation and the protocols used to eradicate the MRSA was collected by assessment of both paper and electronic medical records and pharmacy records for the patients. Four out of the 20 patients were not offered eradication therapy secondary to longstanding documented non-adherence to therapy. Medical and pharmacy records for three out of the 20 patients were incomplete for treatment details and were excluded. Thirteen patients' treatment histories were then analysed. 
Approval for the Australian CF Data Registry was granted by the Western Sydney Local Health District Ethics Committee and all patients gave written informed consent. This subgroup analysis was also approved separately.

\section{Conclusions}

In conclusion, the successful eradication of MRSA is most effective in intermittently colonised subjects. In that situation, the eradication attempt is usually successful when early eradication is achieved; prolonged antibiotic therapy is of little use to achieve eradication.

Author Contributions: Conceptualization, data acquisition, and report writing-review and editing, L.R., Y.S., A.M., P.G.M.

Funding: This research received no external funding.

Acknowledgments: We thank all the adults with Cystic Fibrosis at Westmead who provided all the data, the clinical staff for providing the care for these patients, and the Australian CF Data Registry.

Conflicts of Interest: The authors declare no conflict of interest.

\section{References}

1. Song, Y.; Keatley, L.R.; Middleton, P.G. Methicillin-resistant Staphylococcus aureus in health-care workers with cystic fibrosis in Sydney. Respirol. Case Rep. 2018, 6, e00378. [CrossRef]

2. Hall, H.; Gadhok, R.; Alshafi, K.; Bilton, D.; Simmonds, N.J. Eradication of respiratory tract MRSA at a large adult cystic fibrosis centre. Respir. Med. 2015, 109, 357-363. [CrossRef]

3. Vallières, E.; Rendall, J.C.; Moore, J.E.; McCaughan, J.; Hoeritzauer, A.I.; Tunney, M.M.; Downey, D.G. MRSA eradication of newly acquired lower respiratory tract infection in cystic fibrosis. ERJ Open Res. 2016, 2, 00064-02015. [CrossRef]

4. Kiefer, A.; Bogdan, C.; Melichar, V.O. Successful eradication of newly acquired MRSA in six of seven patients with cystic fibrosis applying a short-term local and systemic antibiotic scheme. BMC Pulm. Med. 2018, 18, 20. [CrossRef]

5. Dasenbrook, E.C.; Checkley, W.; Merlo, C.A.; Konstan, M.W.; Lechtzin, N.; Boyle, M.P. Association between respiratory tract methicillin-resistant Staphylococcus aureus and survival in cystic fibrosis. JAMA 2010, 303, 2386-2392. [CrossRef]

6. Dasenbrook, E.C.; Merlo, C.A.; Diener-West, M.; Lechtzin, N.; Boyle, M.P. Persistent Methicillin-resistant Staphylococcus aureus and Rate of FEV1 Decline in Cystic Fibrosis. Am. J. Respir. Crit. Care Med. 2008, 178, 814-821. [CrossRef]

7. Wood, M.E.; Sherrard, L.J.; Ramsay, K.A.; Yerkovich, S.T.; Reid, D.W.; Kidd, J.T.; Bell, S.C. Methicillin-resistant Staphylococcus aureus acquisition in healthcare workers with cystic fibrosis: A retrospective cross-sectional study. BMC Pulm. Med. 2016, 16, 78. [CrossRef] [PubMed]

8. Chmiel, J.F.; Aksamit, T.R.; Chotirmall, S.H.; Dasenbrook, E.C.; Elborn, J.S.; LiPuma, J.J.; Ratjen, F.A. Antibiotic management of lung infections in cystic fibrosis. I. The microbiome, methicillin-resistant Staphylococcus aureus, gram-negative bacteria, and multiple infections. Ann. Am. Thorac. Soc. 2014, 11, 1120-1129. [PubMed]

9. Muhlebach, M.S. Methicillin-resistant Staphylococcus aureus in cystic fibrosis: How should it be managed? Curr. Opin. Pulm. Med. 2017, 23, 544-550. [CrossRef] [PubMed]

10. Maliniak, M.L.; Stecenko, A.A.; McCarty, N.A. A longitudinal analysis of chronic MRSA and Pseudomonas aeruginosa co-infection in cystic fibrosis: A single-center study. J. Cyst. Fibros. 2016, 15, 350-356. [CrossRef] [PubMed]

11. Langton Hewer, S.C.; Smyth, A.R. Antibiotic strategies for eradicating Pseudomonas aeruginosa in people with cystic fibrosis. Cochrane Database Syst. Rev. 2017, 4, Cd004197. [CrossRef] [PubMed] 
12. Lund-Palau, H.; Turnbull, A.R.; Bush, A.; Bardin, E.; Cameron, L.; Soren, O.; Faust, S.N. Pseudomonas aeruginosa infection in cystic fibrosis: Pathophysiological mechanisms and therapeutic approaches. Expert Rev. Respir. Med. 2016, 10, 685-697. [CrossRef] [PubMed]

13. Smith, W.D.; Bardin, E.; Cameron, L.; Edmondson, C.L.; Farrant, K.V.; Martin, I.; Alton, E.W. Current and future therapies for Pseudomonas aeruginosa infection in patients with cystic fibrosis. FEMS Microbiol. Lett. 2017, 364. [CrossRef] [PubMed]

C 2019 by the authors. Licensee MDPI, Basel, Switzerland. This article is an open access article distributed under the terms and conditions of the Creative Commons Attribution (CC BY) license (http://creativecommons.org/licenses/by/4.0/). 